\title{
A FORMAÇÃO INICIAL DE PROFESSORES PARA O ENSINO DE MATEMÁTICA NA EJA UMA EXPERIÊNCIA VIVENCIADA NO GELEN
}

\author{
THE INITIAL TRAINING OF TEACHERS FOR THE TEACHING OF \\ MATHEMATICS IN EJA AN EXPERIENCE EXPERIENCED IN GELEN
}

\author{
LA FORMACIÓN INICIAL DE LOS PROFESORES PARA LA ENSEÑANZA \\ DE LAS MATEMÁTICAS EN LA EJA UNA EXPERIENCIA EXPERIMENTADA EN \\ GELEN
}

Rosimeire Aparecida Rodrigues ${ }^{1} \mathbf{O}$

\begin{abstract}
RESUMO
No presente texto buscamos compreender como pensar o ensino de matemática na Educação de Jovens e Adultos (EJA) na formação inicial visando a aprendizagem relacionada às práticas contextualizadas com o apoio de recursos tecnológicos. Numa abordagem qualitativa na perspectiva da pesquisaformação. Os sujeitos da pesquisa foram os estudantes do curso de Pedagogia que participam do grupo de estudos de letramento e numeramento (GELEN). As reflexões apresentadas originaram-se das aprendizagens observadas nos momentos de estudo/formação no GELEN. A intenção foi de compreender como as atividades pedagógicas da EJA nas aulas de matemática, com o uso de tecnologias digitais, podem explorar situações que instiguem o pensar e fazer matemático nos momentos de estudos formativos sobre o ensino de matemática. A partir de momentos de discussão sobre recursos pedagógicos digitais para a sistematização de conteúdos matemáticos na sala de aula, foi possível (re)significar a organização pedagógica e dar sentido às atividades propostas com a interação sobre os conteúdos matemáticos. Com as reflexões foi possível perceber que as estudantes da formação inicial se apropriaram de conhecimentos significativos em relação a prática docente com o uso das tecnologias dando importância e sentido às práticas cotidianas e suas correlações com o conteúdo ensinado nas especificidades da EJA.
\end{abstract}

Palavras-chave: Pensamento numérico. Prática docente. Contextualização.

\begin{abstract}
In this text we seek to understand how to think about the teaching of mathematics in Youth and Adult Education (EJA) in initial education aiming at learning related to contextualized practices with the support of technological resources. In a qualitative approach from the perspective of research-training. The research subjects were pedagogy students who participated in the literacy and numbering study group (GELEN). The reflections presented originated from the learning observed in the moments of study/training at GELEN, the intention was to understand how the pedagogical activities of the EJA in mathematics classes with the use of digital technologies can explore situations that suggest the thinking and doing mathematics in the moments of formative studies on the teaching of mathematics. From moments of discussion about digital pedagogical resources for the systematization of mathematical contents in the classroom, it is possible to (re)signify the pedagogical organization and give meaning to the proposed activities with the interaction on mathematical contents. With the reflections it was possible

\footnotetext{
${ }^{1}$ Doutora em Educação ciências e matemática-REAMEC - Universidade Federal do Mato Grosso; Mestre em Mídia e conhecimento pela Universidade Federal de Santa Catarina; Professora Assistente da Universidade Federal do Tocantins - UFT, Campus de Arraias, Arraias, Tocantins, Brasil. Endereço para correspondência: Rua Coronel Joaquim Alves Teixeira, Quadra 09, Lote 6B. CEP: 77330-000 Arraias, Tocantins, Brasil. E-mail: rosimeirear@mail.uft.edu.br
} 
to perceive the students of the initial education appropriated significant knowledge in relation to the teaching practice with the use of technologies giving importance and meaning to daily practices and their correlations with the content taught in the specificities of the EJA.

Key Words: Numerical thinking. Teaching practice. Contextualization.

\section{RESUMEN}

En este texto buscamos entender cómo pensar sobre la enseñanza de las matemáticas en la Educación de Jóvenes y Adultos (EJA) en la educación inicial con el objetivo de aprender relacionado con las prácticas contextualizadas con el apoyo de los recursos tecnológicos. En un enfoque cualitativo desde la perspectiva de la investigación-formación. Los sujetos de la investigación fueron estudiantes de pedagogía que participaron en el grupo de estudio de alfabetización y numeración (GELEN). Las reflexiones presentadas se originaron a partir del aprendizaje observado en los momentos de estudio/formación en GELEN, la intención fue comprender cómo las actividades pedagógicas de la EJA en las clases de matemáticas con el uso de las tecnologías digitales pueden explorar situaciones que sugieren el pensamiento y la realización de las matemáticas en los momentos de los estudios formativos sobre la enseñanza de las matemáticas. A partir de momentos de discusión sobre los recursos pedagógicos digitales para la sistematización de contenidos matemáticos en el aula, es posible (re)significar la organización pedagógica y dar sentido a las actividades propuestas con la interacción sobre contenidos matemáticos. Con las reflexiones se pudo percibir que los alumnos de la educación inicial se apropiaron de conocimientos significativos en relación a la práctica docente con el uso de tecnologías dando importancia y significado a las prácticas cotidianas y sus correlaciones con los contenidos enseñados en las especificidades de la EJA.

Palabras clave: Pensamiento numérico. Práctica docente. Contextualización.

\section{INTRODUÇÃO}

O processo de formação docente exige a compreensão da necessidade de refletir sobre a atuação desde a licenciatura, tornando-se possível a apropriação de conhecimentos que fortaleçam o aprimoramento teórico e metodológico que contribuam positivamente com a formação profissional.

Esse texto apresenta algumas reflexões sobre a formação para o ensino de matemática durante momentos de estudo-formação do Grupo de Estudos em Letramento e Numeramento $(\text { GELEN })^{2}$, e envolve uma trajetória investigativa nas reuniões entre os participantes e a líder durante o primeiro semestre de 2018. Para tal, são lidos e discutidos textos relacionados ao numeramento e letramento e práticas contextualizadas, bem como, aprendizagens nas trocas de experiências, dúvidas e sugestões relacionadas ao cotidiano escolar e a matemática, que é um dos focos do grupo.

\footnotetext{
${ }^{2}$ GELEN: Grupo de Estudos em Letramento e Numeramento ativo desde 2016, com registro na UFT/Cnpq. Link: http://dgp.cnpq.br/dgp/espelhogrupo/212822. 
Os encontros envolvem momentos de estudos teóricos que fundamentam a formação para o ensino de matemática e reflexões sobre a prática docente vivenciada nos momentos de estudo-formação de um grupo de estudantes do curso de Pedagogia a partir das experiências na Educação Básica e discussões alicerçadas por Fiorentini (1995, 2005), Josso (2004, 2008), Fonseca (2004, 2005, 2007, 2012), Mendes (2001, 2004, 2007), Pereira (2013), Pimenta (2002, 2012).

Nos encontros envolvendo a formação para o ensino a partir de ações contextualizadas como preço, data de fabricação e validade, tabela de informações nutricionais, dentre outros para que eles pudessem observar a presença da matemática no cotidiano. Pela reflexão sobre práticas que envolvem o desenvolvimento do cálculo mental e o processo operacional dos algoritmos e pensamento quantitativo, e, situações problema seriam criadas usando a interação entre o conhecimento curricular e o cotidiano.

Alguns autores de suma importância que fundamentaram a pesquisas Ubiratan D’Ambrósio, Kátia Smole, Sérgio Lorenzato, Dario Fiorentini, Cecília Parra, Adair Mendes Nacarato, Maria da Conceição Fonseca, entre outros. Outrossim, estes proporcionaram reflexões sobre a relação teórica e prática na formação docente e nos processos de aprendizagem. Para realização da pesquisa seguimos a metodologia de pesquisa-formação e a abordagem qualitativa, tornando-se possível a participação de forma ativa para descrever as experiências vivenciadas.

A intenção de apresentar essas reflexões sobre o ensino da educação básica, mais precisamente na EJA, foi fazer com que as estudantes na formação inicial compreendessem a necessidade de desenvolverem atividades de forma dinâmica, interagindo com a pesquisadora e a professora da turma para obter um bom resultado no decorrer da pesquisa, buscando mostrar para os alunos a possibilidade de aprender matemática brincando e também buscar aprimorar o ensino e aprendizagem dos alunos.

É preciso pensar na matemática de forma diferenciada e que desperte nos alunos o gosto por essa matéria, que para alguns é tida como a pior ou muito difícil de aprender, e, assim fazer com que eles, de acordo com seu desenvolvimento, compreendam e visualizem de maneira diversificada uma matemática que será sempre presente em suas vidas, bem como na formação docente, que tem instigado os sujeitos a irem em busca de novos conhecimentos, tornando possível aprimorá-los cada vez mais para que tenham novos métodos educativos para atuação em sala de aula e comprometimento com a instituição de ensino em que está inserido. 
Com o intuito de aprimorar a formação docente para o ensino de matemática essa pesquisa teve como questionamento: Como as práticas contextualizadas desenvolvidas na sala de aula podem contribuir com desenvolvimento de atividades matemáticas para o aprimoramento do pensamento numérico e das quantidades?

O objetivo geral da pesquisa esteve voltado em compreender como o pensamento numérico trabalhado durante as aulas, ampliando o estudo de conceitos básicos do currículo no dia a dia, pode contribuir com a formação para o ensino de matemática. Assim, o presente trabalho está organizado da seguinte forma: primeiramente a introdução na qual o tema, o GELEN, o lócus da pesquisa e objetivos são apresentados, em seguida a metodologia da pesquisa, o referencial teórico e após o relato da experiência da prática de numeramento na EJA e algumas considerações.

\section{A FORMAÇÃO PARA O ENSINO DE MATEMÁTICA NA EDUCAÇÃO DE JOVENS E ADULTOS}

Na formação de professores que ensinarão matemática é fundamental a percepção que a prática docente precisa ser repensada, pois, há mudanças com o decorrer do tempo. Haja vista, que tal afirmação pode ser percebida ao longo da história, pois a sociedade vem se adaptado com as transformações de cada época, e é importante poder discutir sobre as inovações na prática docente e na própria formação para o ensino evidenciando que a matemática está presente e inserida em nosso cotidiano.

De acordo com D’Ambrósio (2003) no ensino de matemática, faz-se necessário respeitar a realidade do aluno e gerar segurança e confiabilidade na aprendizagem e desenvolvimento do conhecimento matemático. Para isso, a utilização de situações cotidianas como "compra/venda" aproxima a aprendizagem no ambiente escolar com a matemática presente no comércio, e possibilita assim uma visão crítica a partir da instrumentalização de conceitos de natureza matemática nos diversos contextos.

Nessa linha de pensamento, o processo de compreensão de novas formas de ver e pensar a formação, evidencia-se a necessidade de que as propostas curriculares promovam o desenvolvimento de uma educação que possa constituir habilidades e competências que contribuam com a formação de um aluno enquanto cidadão ativo e agente da própria aprendizagem, (COURA, PASSOS, 2017). 
Os professores quando passam a atuar na sala de aula deparam com grandes dificuldades na prática docente da disciplina de matemática. Nesse sentido, a formação no curso de Pedagogia tem como função possibilitar a esses futuros professores uma aproximação entre a teoria e a prática, para que se desmistifique a visão de que essa relação está distante, podendo superar as próprias dificuldades, e, considera-se que a universidade em seus muitos projetos pode ampliar os conceitos e conhecimentos formando agentes capazes de lidarem de forma ativa com as necessidades didático-pedagógicas no e para o ensino de matemática.

Para o ensino de matemática os professores em formação precisam ser inseridos nas discussões sobre a prática docente, no sentido de compreenderem como as mudanças realizadas em documentos orientadores e norteadores das propostas ocorrem. Diante disso, faz-se necessário que considerem que os livros didáticos, as práticas contextualizadas, a linguagem simbólica, os códigos e notações apresentados precisam contemplar os mais diversos contextos matemáticos (COURA; PASSOS, 2017).

$\mathrm{O}$ ensino de matemática tem sido motivo de inúmeros debates entre teóricos e pesquisadores. Essa matéria por muitas vezes e motivo, é vista com um sentimento de abominação/medo por parte de alguns alunos por possuir um estigma de matéria difícil e/ou até impossível. Por outro lado, os professores responsáveis por ensinar e encarregados de desconstruir essas ideias, às vezes não possuem conhecimentos pedagógicos e metodológicos adequados, visto que, partem de uma formação insipiente que foca apenas em teorias e metodologias e não em conteúdos e ensino aprendizagem.

Alguns profissionais dessa área partem de pressupostos teóricos e se preocupam em ensinar apenas conceitos vazios e fórmulas que não fazem o menor sentido para os alunos que acompanham suas aulas, o que dificulta o processo de apropriação do conteúdo e impossibilita o diálogo entre professor e aluno.

A matemática está sempre presente nas atividades diárias, dessa forma, sua percepção/aprendizagem é fundamental em nossas vidas. E, a partir das representações na realidade do aluno, seja com dinâmicas, brincadeiras, atividades interdisciplinares entre outros passos que possibilitariam a melhor compreensão do educando e os familiarizassem com a matemática.

[...] a exploração de uma grande variedade de ideias matemáticas relativas a números, medidas, geometria e noções rudimentares de estatística, de forma que as crianças desenvolvam e conservem um prazer e uma curiosidade acerca da matemática. Uma proposta assim incorpora contextos do mundo real, as 
experiências e a linguagem natural da criança no desenvolvimento das noções matemáticas, sem, no entanto, esquecer que a escola deve fazer o aluno ir além do que parece saber, deve tentar compreender como ele pensa e fazer as interferências no sentido de levar cada aluno a ampliar progressivamente suas noções matemáticas (SMOLE, 2003, p.62).

Para isso, o professor precisa ir muito além de apenas ensinar, para se obter resultados é necessário refletir sobre aquilo que se ensina, é preciso ter prazer em ensinar e o mais importante ter domínio/saber o que se ensina, devido a isso é imprescindível manter-se sempre atualizado, com pesquisas, especializações entre outros métodos. Nesse sentido, uma reflexão sobre o ensino de matemática na EJA, faz-se necessário salientar a preocupação com o processo de significação dos conteúdos e compreensão sobre as especificidades dessa modalidade de ensino.

Nessa direção, é primordial que as práticas docentes envolvam a "busca do sentido de ensinar e aprender matemática, o que remete à questões de significação da matemática que é ensinada e aprendida. [...] o sentido se constrói à medida que a rede de significados ganha corpo, substância e profundidade" (FONSECA, 2007, p. 75).

Nóvoa (1995), afirma a necessidade do ato de "aprender contínuo é essencial se concentra em dois pilares: a própria pessoa, como agente, e a escola, como lugar de crescimento profissional permanente", ou seja, a formação continuada deve partir também da escola em comunhão com os docentes para que juntos desenvolvam um ensino de qualidade e que sirva de estímulo ao aluno.

Nos dias atuais a relação professor e aluno não é mais baseada em uma perspectiva de autoridade, mas sim, pelas metodologias que ele oportuniza, pelos seus conhecimentos da disciplina, sobre como ele mantém o aluno interessado em sua aula tornando o aprendizado mais humano e menos mecanizado. Ser professor hoje é ser mediador do ensino, é ter um papel decisivo na trajetória do aluno.

[...] ninguém poderá ser um bom professor sem dedicação, sem preocupação com o próximo, sem amor num sentido amplo. O professor passa ao próximo aquilo que ninguém pode tirar de alguém, que é o conhecimento. Conhecimento só pode ser passado adiante, por meio de uma doação. O verdadeiro professor passa o que sabe não em troca de um salário (pois, se assim fosse, melhor seria ficar calado 49 minutos!), mas somente porque quer ensinar, quer mostrar os truques e os macetes que conhece (D’AMBRÓSIO, 2012, p. 77). 
Essa percepção evidencia que o professor ao se dedicar à formação de qualidade, terá mais resultados e também estará atento, visto que, sempre nos deparamos com salas heterogêneas e, como esclarece Vygotsky (1996), o educador deve ter metodologias de ensino diferenciadas e entender que os alunos não desenvolvem os mesmos conhecimentos nem aprendem da mesma forma e no mesmo espaço de tempo.

$\mathrm{Na}$ atualidade, ensinar torna-se cada vez mais uma tarefa desafiadora, já que, as crianças tornaram-se mais críticas, observadoras e questionam muito mais. O professor em sala não é mais considerado o único detentor do saber, pois os alunos também possuem suas experiências e querem expor seu ponto de vista e/ou ideias. Daí, a necessidade de (re)pensar os paradigmas que permeiam a matemática, de romper com os velhos hábitos de ensino, de possibilitar a oportunidade de participação, transformar a sala de aula em um,

[...] espaço reservado ao desenvolvimento de uma comunicação interativa, no qual os alunos possam interpretar e descrever ideias matemáticas, verbalizar os seus pensamentos e raciocínios, fazer conjecturas, apresentar hipóteses, ouvir as ideias dos outros, argumentar, criticar, negociar o significado das palavras e símbolos usados, reconhecer a importância das definições e assumir a responsabilidade de validar seu próprio pensamento[...] (D’ANTONIO, 2004, p. 32).

Nesse processo de interação na realidade da EJA, observa-se a necessidade de olhar a realidade atual com uma prática docente que envolva a superação de que a matemática é distante, ainda hoje estamos presos as fórmulas matemáticas que não tem nenhuma significação aos alunos e que os fazem questionar para que usaram aquilo em sua vida adulta, eles acabam se perdendo em um mar de técnicas e truques, visando apenas em lembrar de tudo até a próxima prova. Isso, pode ocorrer a partir da proposição de situações problematizadas que promovam a capacidade de interpretação do problema, da análise dos dados e suas possíveis correlações com diferentes contextos como do convívio familiar, social e cultural.

Sendo assim, ao pensar em formação de professores, faz-se necessário a superação da insuficiência do ensino nos cursos de licenciatura, revertendo o despreparo dos docentes aos serem inseridos em sala, tanto em conteúdos quanto em lidar com os alunos. Ser professor é analisar mais sobre o conteúdo colocado em sala de aula para ajudar o aluno a desenvolver e ter aprendizado mais elevado, desenvolver a capacidade de cada um e de seus conhecimentos e possibilitar ao aluno o aprender do conteúdo de forma mais ampla.

A modalidade de educação EJA é uma oportunidade de ensino para as pessoas que, 
quando mais novas não puderam estar em uma escola, ou não tiveram acesso à educação por vários motivos, e com a oferta desse ensino podem associar o trabalho, a família e a escola.

Com a evolução da tecnologia e o acesso rápido à informação, é imprescindível não pensar em fazer uso de recursos como o computador e o celular para a formação escolar, e não apenas a formação de crianças e adolescentes, mas também dos adultos e idosos, que estão na escola buscando o aprendizado, e têm acesso ou possuem computador e celular, que podem ser utilizados para aprendizagem.

Nesse processo de desenvolvimento, o papel do professor como inovador da prática docente é fundamental para que a inserção das tecnologias como recurso de apoio pedagógico e metodológico, promova a interação da turma com esses recursos articulando a relação entre os conteúdos propostos e os conhecimentos matemáticos. Nesse sentido, a escola também precisa estar em parceria com o professor, dando-lhe liberdade para levar as ferramentas tecnológicas como forma de acesso ao saber para suas aulas e fornecendo apoio técnico e material para que esse trabalho seja de qualidade.

Este artigo tem como objetivo refletir sobre a aprendizagem docente na modalidade de ensino EJA com a utilização das ferramentas tecnológicas como o blog e o WhatsApp durante as aulas ou para atividades de casa visando a apropriação dos conceitos matemáticos operacionais em situações contextualizadas. Exige-se da formação para a docência, leituras sobre essa modalidade de ensino e pesquisas sobre situações de investigação adequadas à turma em que a proposta será desenvolvida para o momento do planejamento das aulas.

O trabalho justifica-se pela sua contribuição para a inserção das ferramentas tecnológicas na modalidade de ensino EJA, tendo em vista o desenvolvimento educacional e social dos jovens e adultos com o intuito de aproximar os conteúdos trabalhados na sala de aula dos conteúdos matemáticos de situações contextualizadas em ambientes digitais on-line compartilhadas no WhatsApp.

A educação de jovens e adultos possibilita aos que não conseguiram estudar na idade apropriada, concluir seus estudos, e refletir sua trajetória se faz necessário para que seu valor seja reconhecido, bem como para a atuação docente e seus desafios para o processo de ensino e aprendizagem. Para isso dentre diversos documentos, livros e autores que abordam o tema, nos basearemos em Brasil (2002) e Ribeiro (2014).

Esse artigo segue a seguinte sequência, primeiramente será abordado o ensino de matemática na EJA, a trajetória histórica da EJA no Brasil, seus avanços e retrocessos; em 
sequência serão discutidos os aspectos conceituais da tecnologia em sua inserção na educação; seguindo será abordado a utilização do blog e do WhatsApp na sala de aula, os aspectos didáticos e metodológicos apresentando a metodologia da pesquisa e também a descrição da mesma, e, por fim as considerações finais.

\subsection{EJA no Brasil: breve contexto histórico}

A Educação de Jovens e Adultos no Brasil é uma modalidade de ensino, que vem enfrentando transformações com modificações que representam tanto avanços positivos quanto alguns retrocessos. Para muitos a EJA é apenas um meio para que as pessoas que não conseguiram se formar na idade certa, possam "correr atrás do atraso" e dar continuidade aos seus estudos mesmo em idade avançada.

Brasil (2002, p.13), fala que "[re]construir a trajetória da educação de jovens e adultos no Brasil é tarefa complexa, pois não existem registros suficientes em relação às diversas ações implementadas, em especial no âmbito não-governamental". E essa realidade vinha desde a colonização, sobre isso Brasil (2002), nos diz que, algumas ações foram voltadas para a educação do adulto na era colonial, porém todas com interesse religioso ou do império, e nenhuma dessas ações visavam a real aprendizagem do adulto, uma vez que, na época somente as pessoas abastadas tinham direitos.

Ainda nessa linha histórica da EJA, Brasil (2002, p.13) "Na segunda década do século 20, muitos movimentos civis, e mesmo oficiais, se empenharam na luta contra o analfabetismo, considerado 'mal nacional' e 'uma chaga social'. Nessa época houve uma grande necessidade de formação de mão de obra, devido ao crescimento urbano trazido pela indústria nacional. Nesse sentido Brasil (2002, p.14),

[n]essa época, o Decreto n. ${ }^{\circ}$ 16.782/A, de 13 de janeiro de 1925, conhecido como Lei Rocha Vaz, ou Reforma João Alves, estabeleceu a criação de escolas noturnas para adultos. Foi apenas na década de 40 que a educação de jovens e adultos se firmou como questão de política nacional, por força da Constituição de 1934, e instituiu nacionalmente a obrigatoriedade e a gratuidade do ensino primário para todos.

É interessante destacar que, mesmo sendo decretado a criação de escolas noturnas para os adultos em 1925, apenas na década de 40 a educação de jovens e adultos passou a ser vista como questão política nacional, devido a constituição de 1934 que garantiu a obrigatoriedade e gratuidade do ensino primário a todos. 
O autor Ribeiro (2014, p.28) sobre os anos 50 vem nos dizer que eles “[...] destacaramse como políticas educacionais para a educação de pessoas jovens e adultas: a Campanha Nacional de Educação Rural (1952) e a Campanha Nacional de Erradicação do Analfabetismo (1958), com curta duração e poucas realizações". De acordo com o autor percebemos que, em meio aos avanços essa modalidade de ensino não escapou de alguns retrocessos.

Brasil (2002, p.15) “[n]os seus primórdios, a educação de jovens e adultos era oferecida apenas em nível equivalente ao ensino primário; a partir de 1960, foi estendida ao curso ginasial.” Essa foi uma grande conquista para a EJA, pois assim os jovens e adultos poderiam dar continuidade a sua formação escolar. Paulo Freire nessa época, também foi muito importante para a EJA, assim Brasil (2002, p. 15):

[n]a década de 60, a referência principal para a constituição de um novo paradigma teórico e pedagógico foi dada pelo educador Paulo Freire, cujo papel fundamental no desenvolvimento da EJA no Brasil, ao destacar a importância da participação do povo na vida pública nacional e o papel da educação para sua conscientização.

Ao refletirmos sobre o trecho, podemos observar que, Freire percebia a grande necessidade de formação escolar para o adulto, e também que a educação dada a eles precisaria ser diferente. Brasil (2002, p.15) "Em janeiro de 1964, foi aprovado o Plano Nacional de Alfabetização, que previa a disseminação, por todo o Brasil, de programas de alfabetização orientados pela proposta de Paulo Freire". Entretanto, com o golpe militar o programa foi suspenso.

Ainda sobre os anos de 1960, de acordo com Ribeiro (2014), vale destacar que este foi um dos momentos mais importantes para a EJA no Brasil, tendo em vista que, nessa época muitas ações, tanto civis quanto governamentais, foram criadas para combater o analfabetismo e promover a continuidade da educação para esse público.

A educação de jovens e adultos recebeu uma atenção especial nessa época, e mesmo com o golpe militar ações voltadas para a alfabetização ainda eram desenvolvidas por algumas igrejas, espaços comunitários e também em associações de moradores. Segundo Brasil (2002, p.15):

[e]m 1967, o governo federal organizou o Movimento Brasileiro de Alfabetização (Mobral), iniciando uma campanha nacional maciça de alfabetização e de educação continuada para jovens e adultos. Em 1971, com a Lei de Diretrizes e Bases da Educação Nacional (n. ${ }^{\circ}$ 5.692/71), foi implantado o ensino supletivo. 
O movimento brasileiro de alfabetização (MOBRAL) foi criado com o objetivo de alfabetizar e letrar jovens e adultos, e de certa forma diminuir o índice de analfabetismo da época que era alarmante. Sobre a implementação do ensino supletivo Brasil (2002, p.16), "“...] ele se destinava a 'suprir a escolarização regular para adolescentes e adultos que não a tinham seguido ou concluído na idade própria'. E, continuou a se expandir, sendo instituído por todo território do país e tendo sua atuação diversificada. Brasil (2002, p.15), “[u]ma de suas iniciativas foi o Programa de Educação Integrada (PEI), que condensava o primário em poucos anos e abria a perspectiva de continuidade dos estudos aos recém-alfabetizados do Mobral", desse modo aqueles que queriam dar continuidade aos seus estudos tinham mais oportunidades de ensino até o fim da ditadura.

Em 1985 aconteceu a implementação da Fundação Educar que consistia em promover $\mathrm{o}$ atendimento as séries iniciais do ensino fundamental, sendo responsável pelos materiais e avaliações de atividades, essa fundação foi extinta em 1990, e os órgãos públicos assim como outras instituições passaram a ser responsáveis pela educação dos jovens e adultos no país. Brasil (2002, p.17),

Outra ação importante no Brasil para o ensino de jovens e adultos, foi uma seção dedicada a ela na Lei de diretrizes e bases da educação nacional (LDBEN), segundo Brasil (2002, p.17):

[n]a LDBEN n. ${ }^{\circ}$ 9.394/96, a seção dedicada à educação básica de jovens e adultos reafirmou o direito destes a um ensino básico adequado às suas condições, e o dever do poder público de oferecê-lo gratuitamente, na forma de cursos e exames supletivos. A lei alterou a idade mínima para realização de exames supletivos para 15 anos, no Ensino Fundamental, e 18, no Ensino Médio, além de incluir a educação de jovens e adultos no sistema de ensino regular.

Surge assim, um novo olhar dado ao ensino de adultos, de acordo com Ribeiro (2014, p.32-33), tornando possível assumir "dignidade própria com a implantação da Lei 9394/96, a educação de pessoas jovens e adultas além de passar a fazer parte constitutiva da lei, tornou-se uma modalidade da Educação Básica nas etapas dos ensinos Fundamental e Médio”. Os jovens e adultos por lei, passam a ter o direito de ter uma educação específica voltada para eles. Brasil (2002, p.17): 
assumindo a de reparação, equidade(sic) e qualificação - o que representa uma conquista e um avanço.

Com essa nova definição, a educação de jovens e adultos passa a ser vista como um direito do cidadão e não mais um simples suprimento do tempo perdido. Essa nova visão da EJA é um avanço para esta modalidade de ensino que, até hoje faz a diferença na vida daqueles que, por algum motivo não conseguiram concluir seus estudos por um processo contínuo. Com isso, é possível perceber o quanto a trajetória da EJA foi cercada por momentos difíceis, e também gloriosos que possibilitam a continuidade da modalidade até o nosso atual contexto histórico, assim como, pensar nos avanços educacionais da atualidade para a EJA também é muito importante. Nesse sentido a inserção das tecnologias podem ser um ótimo recurso para o ensino e aprendizagem na educação de jovens e adultos.

O presente texto vem apresentar alguns aspectos em relação a formação para o ensino de matemática, a partir de discussões acerca da inserção dos recursos tecnológicos na prática de sala de aula pensando nos avanços tecnológicos e também em como utilizar esses recursos que crescem a cada dia para promover uma educação de qualidade (PONS, 2001; SANCHO, 2001; KENSKI, 2009).

\section{PERCURSO METODOLÓGICO}

O GELEN e a formação na aproximação entre a teoria e a prática oportunizaram situações formativas que possibilitaram a realização dessa pesquisa, de caráter qualitativo que se caracteriza pelos pressupostos da pesquisa-formação, no intuito de compreender o processo de formação a partir de reflexões diante de experiências vivenciadas por um grupo de estudantes do curso de Pedagogia no que tange a aprendizagem da e para a docência no e para o ensino de matemática nos anos iniciais.

O ensino de Matemática nos anos iniciais exige dos professores um processo de investigação teórica e prática, tornando possível um movimento que possa integrar o conhecimento matemático escolar ao conhecimento da e na prática social para promover uma nova visão sobre a prática na sala de aula que possa dar sentido e significação aos conteúdos.

Diante disso, as discussões no GELEN são pautadas na aprendizagem do e para o ensino de matemática, sendo concebida a necessidade de compreender que: 
a) Professor(a) e aluno(a) precisam superar a ideia que na matemática do dia a dia pode contribuir com a matemática escolar.

b) A necessidade de compreender nas atividades propostas que o sentido e o significado dos conteúdos podem descontruir as frustrações de muitos(as) alunos(as).

c) A importância de compreensão do conceito de números e de quantidades.

d) A prática docente investigativa e compartilhada das futuras professoras podem colaborar com novas formas de ensinar matemática na sala de aula.

Para isso, consideramos fundamental que nas discussões durante os momentos de estudo-formação, no sentido de promover a percepção e a compreensão de que as atividades precisam "expressar ou explicitar a estrutura de uma situação-problema e a presença de generalização" (FIORENTINI, MIORIM; MIGUEL, 1993, P. 87).

No GELEN as discussões nos encontros quinzenais durante o primeiro semestre de 2018 envolvem estudos teóricos e reflexões sobre as experiências vivenciadas pelas estudantes do curso de Pedagogia com o intuito de fortalecer a formação dessas que atuarão na Educação Básica. Nesse contexto, apresentamos alguns momentos pertinentes a formação para o ensino na Educação de Jovens e Adultos que proporcionaram às participantes do grupo uma ampliação do conhecimento acadêmico sobre a prática docente nessa modalidade de ensino trazendo contribuições formativas, que visam compreender como a formação para o ensino de matemática pode superar as dificuldades diante do enfrentamento do pensamento matemático e situações que a envolvem.

No grupo de estudos GELEN os pesquisadores procuram articular a relação teóricoprática e os seus procedimentos metodológicos no sentido de promover a relação entre a formação acadêmica e a prática docente. Para isso, pesquisa correntes conceituais que englobam a formação de professores que ensinam matemática nos anos iniciais tendo como finalidade inter-relacionar a matemática escolar com a matemática do dia a dia.

No campo das pesquisas sociais, além de descrever e compreender, pretende-se modificar uma realidade" (GELEN, 2017), a qual esta metodologia se identifica com a pesquisa-formação com o propósito de desencadear na prática docente um movimento dinâmico que possa articular a relação teórico-prática, fortalecendo as significações da experiência humana diante da capacidade de (re)construção de conceitos profissionais.

Assim, as estudantes/pesquisadoras desse grupo de estudo buscam participar da realidade investigada, tem busca ativa na avaliação e busca de respostas. Para isso, a pesquisa- 
formação promove a experimentação do processo real sobre o modo que os pesquisadores ao compartilhar suas vivências e experiências de forma consciente, contribuam de forma coletiva com a percepção da necessidade de flexibilidade no planejamento.

Nos trabalhos científicos o procedimento ético é um fator fundamental para preservar a identidade dos sujeitos envolvidos na pesquisa. Nesse sentido, as participantes dessa pesquisa são também membros do grupo pesquisado. Esse texto, expressa o olhar observador da pesquisadora sobre o processo formativo para a formação docente, sendo assim, nessa pesquisa os dados foram retirados dos registros dos momentos de estudo-formação não identificando os sujeitos apenas a ocorrência de situações de aprendizagem da e para a docência.

O grupo em seus estudos, reflexões e discussões ampliam conceitos, fundamentos e teorias sobre os conhecimentos pedagógicos, a formação das aprendizagens docentes, e, desenvolve práticas com a atuação no espaço da sala de aula, buscando aprender pela prática e suas relações com o processo de pesquisa, que se constitui em momentos como: a escolha da temática da pesquisa para a prática; a colocação dos problemas; o lugar da teoria; o plano de ação, o processo de observação, investigação e aprendizagem com a prática; abordagem qualitativa; e, apropriações sobre ensino e aprendizagem.

Portanto, considera-se que a proposição formativa com ações oportunizou ao grupo vivenciar momentos de partilha que possam contribuir com a capacidade de compreender a si e ao outro para melhor entender e significar os próprios pensamentos. E, assim, pensa-se em promover a valorização do processo formativo para o conhecimento e desenvolvimento da percepção sobre a importância da reflexão para a formação na aprendizagem para o trabalho docente.

\section{ANÁLISE DOS RESULTADOS}

Apresentamos algumas reflexões significativas quanto a pesquisa considerando os aspectos teóricos e práticos diante das discussões realizadas nos momentos e estudo-formação nos encontros do grupo GELEN, em relação a prática envolvendo situações matemáticas contextualizadas com o apoio de recursos tecnológicos como ferramentas de apoio e pesquisa nas aulas de matemática no primeiro ano da EJA. 


\subsection{A inserção da tecnologia educativa na EJA}

A utilização das tecnologias em sala de aula representa possíveis respostas para problemas ou necessidades de proporcionar um ensino de qualidade a um grupo, e que todos fazem uso de alguma tecnologia em suas aulas. Dessa forma é possível perceber que, para cada dificuldade que surgir sempre haverá a tecnologia para supri-la. Considerando a tecnologia associada à educação Sancho (2001, p.40), nos diz que:

[t]odos utilizam alguma tecnologia em suas aulas. As expositivas, o agrupamento dos alunos segundo a idade, os livros-texto, etc., foram e são outras tantas respostas aos problemas gerados pela necessidade (ou pela decisão) de proporcionar ensino a toda uma coletividade de cidadãos e cidadãs de forma obrigatória ou voluntária.

Sobre as mudanças tecnológicas Kenski (2009), salienta que desde os primórdios da civilização todas as eras estão ligadas ao predomínio de uma certa tecnologia e que o desenvolvimento social do homem também está relacionado a elas.

Para tratar sucintamente da linha histórica da tecnologia Pons (2001, p.51), destaca que "[a] tecnologia educativa como campo de estudo e como disciplina acadêmica tem seu desenvolvimento nos Estados Unidos, principalmente a partir da década de 40”. Para esse autor, o primeiro fim educativo da tecnologia se deu com a utilização de recursos audiovisuais com intuito formativo para especialistas militares durante a segunda guerra mundial.

Pons (2001, p.52) afirma que "[d]urante os anos 50 a psicologia da aprendizagem vai sendo incorporada como campo de estudo dos currículos de tecnologia educacional". Nesse sentido de acordo com o autor, as mudanças nos modelos de aprendizagem que ocorreram nesses anos, influenciaram no desenvolvimento da tecnologia educacional como matéria dos currículos pedagógicos. E, na década de 60 se tem o desenvolvimento dos meios de comunicação de massa, e esse acontecimento também irá influenciar a tecnologia educativa na época, indo para os anos 70, a partir deles o desenvolvimento da informática consolidou o uso dos computadores com fins educativos.

Kenski (2009) destaca os avanços tecnológicos, o ritmo de ensino e aprendizagem precisam ser modificados, assim como a adaptação e permanente aprendizagem ao novo. Partindo da ideia da autora, e do breve contexto histórico apresentado, ter a tecnologia com suas infinitas possibilidades como auxiliar na educação precisa ser tarefa contínua. Assim, utilizar a 
funcionalidade e disponibilidade de ferramentas tecnológicas muitas vezes gratuitas é uma vantagem que precisa ser aproveitada.

No trabalho compartilhado com o grupo os recursos tecnológicos foram utilizados no intuito de contribuir com os procedimentos pedagógicos para uma turma de EJA do primeiro ano do ensino médio, na Escola Estadual Silva Dourado, com atividades matemáticas que envolveram a investigação de situações aritméticas no processo de operações básicas, com uma proposta de contextualizar a matemática do currículo da EJA em situações reais utilizando-se de recursos digitais para a investigação e troca de atividades que envolvessem o pensamento matemático operacional.

A atividade desenvolvida foi apresentada ao coordenador pedagógico e a professora que atuava na turma. $\mathrm{O}$ trabalho com a turma iniciou-se com uma roda de conversa, explicando que seriam utilizados os recursos do WhatsApp para a disciplina conforme o planejamento envolvendo o processo investigativo e a inserção das tecnologias no processo de leitura e interpretação de situações problemas. Assim ficou decidido que o uso do blog seria durante as aulas no laboratório de informática (LABIN) da escola, mas quem quisesse acessá-lo fora da escola poderia.

A atividades envolveram a visita de sites, criação de um blog e trocas de atividades por meio do WhatsApp, principalmente no processo de desenvolvimento do uso do pensamento matemático no que tange aos aspectos operacionais, leitura escrita e contagem.

As propostas envolveram situações de compra e venda, explorando panfletos, receitas entre outras do contexto do dia a dia como produtos, valores, datas, temporalidade, medidas, calendário envolvendo os conteúdos curriculares contidos na proposição da disciplina de matemática nos anos iniciais, transformando as formas de ensinar matemática.

Outro aspecto significativo a ser considerado envolve os materiais usados durante as aulas, pois desde o princípio podem ser convidados a participar como sujeitos ativos na experiência no sentido de que os próprios alunos compartilham informações sobre as situações matemáticas quanto ao uso dos números e as operações.

Nesse sentido, destaca-se a importância da utilização de coisas simples e de fácil acesso durante as aulas, possibilitando mostrar para os alunos que podemos aprender de diversas formas e com materiais diferentes, principalmente na matemática que está presente em todos os momentos como: na quantidade do café que colocamos no copo, no horário que acordamos ou dormimos, na nossa idade, na hora, na altura, no tempo de duração das tarefas realizadas, 
nos preços de produtos e serviços, dentre outras situações diárias ressignificando o sentido da aprendizagem escolar.

Através das discussões no grupo GELEN, o processo de (re)significação pôde ser despertado, e o olhar do professor em formação sobre a participação de todos os alunos, ao serem instigados a pensar e vivenciar na prática em situações matemáticas nos momentos de investigação em que envolvessem o pensamento matemático em ações como fazer compras online (em lojas, sites e panfletos), pensar na quantidade de produtos que podem ou não comprar, usando o conhecimento matemático para analisarem a quantidade de dinheiro suficiente para pagar, sobre quantos e quais produtos podem ser escolhidos, e, se o valor está ou não dentro do orçamento pessoal e/ou familiar.

Em todas as situações exploradas os processos de leitura, interpretação e contagem foram considerados como aspectos fundamentais para a compreensão dos conteúdos, e, também em se tratando de uma turma do primeiro ano da EJA, muitos dos alunos estavam a algum tempo fora da escola e não tinham muita afinidade com o uso desses recursos (blog, sites e WhatsApp) por mais simples que esses representem nos dias atuais. O processo de leitura e interpretação foi muito explorado em situações do dia a dia, com o intuito de aproximar os conteúdos da sala de aula com a realidade que os cercava.

No PCN (1997):

Tradicionalmente, a prática mais freqüente no ensino de Matemática era aquela em que professor apresentava o conteúdo oralmente, partindo de definições, exemplos, demonstração de propriedades, seguidos de exercícios de aprendizagem, fixação e aplicação, e pressupunha que o aluno aprendia pela reprodução. Considerava-se que uma reprodução correta era evidência de que ocorrera a aprendizagem.

Sobre o ensino de matemática, é importante que o professor estude continuamente métodos para que seja possível seus alunos desenvolverem suas capacidades e formas de pensar através das experiências que vivenciam durante as aulas. A partir do momento que se cria uma atividade de matemática ou para qualquer disciplina, faz-se necessário o uso de conteúdos que além de auxiliar no aprendizado estimulem os alunos a pensar e interagir numa troca de conhecimentos.

Nesse sentido "[...] o reencontro do prazer no fazer, no tocar, no desafiar e no reconstruir caminhos responsáveis por despertar um aprender com alegria", de modo que seja possível "um 
diálogo entre o saber fazer e o aprender em suas práticas desencadeando novas pesquisas e novas reflexões" (BARRETO; PRADO, 2012, p.17).

A formação de professores para o ensino da Matemática na EJA é um desafio, já que, o processo de formação de professores não é algo que sempre permanece com eles, dessa forma devem estar em constante desenvolvimento, seja através das leituras no livro, palestras, que vão aprimorar a prática docente em sala de aula, fazendo com que o educando seja motivado a aprender matemática. Tendo o objetivo de compreender o valor da formação da prática pedagógica dos educadores do Ensino de Matemática para despertar o interesse de o educando aprender.

Assim sendo, o ensino de Matemática com sentido e significado é muito importante para os alunos, e ajuda a desenvolver nos pensamentos racionais, que é importante na construção dos conhecimentos que serão constituídos ao longo da Educação Básica.

No processo formativo é essencial que o professor seja capaz de fazer apontamentos sobre a importância que a Matemática ensinada e aprendida na escola tem no dia a dia. Na EJA, os alunos podem ter dificuldade de aprender matemática por motivo de não saberem escrever e nem a ler. Dessa maneira, os professore tem de pensar o que deve fazer para trabalhar esta questão com os alunos.

Portanto, o processo de ensino e aprendizagem da e para a docência precisa proporcionar ao estudante em formação oportunidades de pesquisar, investigar, conhecer a realidade da sala de aula e compartilhar essas experiências de modo que apreenda conhecimentos que sejam reflexos da realidade profissional.

\section{CONSIDERAÇÕES FINAIS}

Esse texto buscou apresentar reflexões sobre a formação para o ensino de matemática a partir de estudos/formativos realizados nos encontros do grupo GELEN, e a relação com a formação docente para o ensino de matemática na EJA viabilizando o processo de ensino envolvendo a leitura, a escrita e contagem na aulas de matemática com o auxilio de práticas investigativas com a inserção de recursos como blog, sites e WhatsApp promovendo o uso da tecnologia no ensino e a interação de conteúdos matemáticos dentro e fora da sala de aula.

Com o processo de significação das atividades trabalhadas em sala de aula e dando sentido aos conteúdos em situações investigadas pelos alunos, tendo em vista a compreensão 
dos processos operacionais básicos, das situações de utilização do pensamento numérico e das quantidades no cotidiano em diversos contextos.

Fazendo-se necessário pensar em utilizar as tecnologias para a EJA pode resultar numa ótima experiência, nos momentos de socialização da pesquisa que os alunos tinham algumas dúvidas em como usar principalmente algumas ferramentas do computador e se apresentavam muito interessados.

O apoio e disponibilidade de acompanhamento e orientação nas atividades de postagem no blog e no WhatsApp, também foi considerada como algo importante para a compreensão de que os alunos não estavam ali fazendo uma tarefa só por fazer, mas que a aprendizagem era fundamental, considerando o computador e o celular como ferramentas que otimizavam o fazer pedagógico dentro e fora das aulas.

A partir das reflexões sobre o ensino da EJA o uso das tecnologias de forma colaborativa e com a utilização de ferramentas como o celular (que grande maioria possui) e o computador (que a própria escola oferece) e outras várias ferramentas digitais, pode ser um ótimo aliado ao processo de ensino e aprendizagem.

Expressando assim a relevância de conhecer e estudar a história da modalidade para após realizar a pesquisa em campo; estudar a inserção da tecnologia na EJA ao conhecer sua história e avanços; a importância do blog e do WhatsApp no desenvolvimento de práticas docente proporcionando uma aproximação entre a tecnologia e a significação dos conteúdos de forma colaborativa.

Nesse sentido, o uso das tecnologias na educação de jovens e adultos é importante para o desenvolvimento escolar e social dos alunos, levando em consideração que, muitos pretendem ampliar seus estudos, buscam um bom emprego, passar em um concurso e utilizar as tecnologias na sala de aula para aprendizagem.

Portanto, é pertinente destacar que iniciativas como o uso das tecnologias na Educação de Jovens e Adultos fornecem oportunidades de aprendizagem que a tecnologia, tendo o professor como orientador nesse processo de ensino e aprendizagem viabilizam.

Por fim, salientamos a importância de compreender na formação dos futuros professores quanto ao sentido e a significação dos conteúdos nas atividades contextualizadas nas aulas de matemática, bem como as concepções pedagógicas a partir da partilha de experiências vivenciadas no fortalecimento dos conhecimentos da e para a docência. Assim, o processo formativo no GELEN contribui com a formação para o (re)pensar sobre a formação consigo e 
com o outro, sendo relevante a promoção e (trans)formação, demonstrando a importância de ampliação das concepções matemáticas em prol das aprendizagens para o ensino.

\section{REFERÊNCIAS}

BRASIL. Referencial Curricular do Ensino Fundamental das escolas públicas do Estado do Tocantins: Ensino Fundamental do $1^{\circ}$ ao $9^{\circ}$ ano. 2. ed. Secretaria de Estado da Educação e Cultura. Palmas -TO, 2018.

BRASIL. Lei no 9.394, de 20 de dezembro de 1996. Estabelece as diretrizes e bases da educação nacional. Disponível em: www.planalto.gov.br/ccivil_03/Leis/L9394.htm. Acesso em: 10 de out. de 2019.

COURA, Flávia Cristina Figueiredo. Matemática e Língua Materna: propostas para uma interação positiva. Ouro Preto, MG, 2005. Monografia (especialização) - Universidade Federal de Ouro Preto, Instituto de Ciências Exatas e Biológicas.

COURA, Cristina Figueiredo. PASSOS, Cármen Lúcia Brancaglion. Estado do conhecimento sobre o formador de professores de Matemática no Brasil. Zetetiké (online), v. 25, p. 7, 2017.

D’ ANTONIO, Sandra. Linguagem e educação matemática: uma reação conflituosa no processo de ensino? 188 f. Dissertação (Mestrado em Educação para a Ciência e o Ensino da Matemática) - Universidade Estadual de Maringá, 2006. KENSKI, Vani Moreira. Tecnologias e Ensino presencial e a distância. $7^{\circ}$ ed. Campinas, São Paulo: Papirus, 2009.

D’AMBROSIO, Ubiratan. Educação Matemática: da teoria à prática. Campinas: Papirus, 1996.

FIORENTINI, Dario; NACARATO, Adair Mendes. (Orgs.) Cultura, formação e desenvolvimento profissional de professores que ensinam matemática. Investigando e teorizando a partir da prática. São Paulo: Musa Editora; Campinas/SP, 2005.

FIORENTINI, D.; MIORIM, M. A.; MIGUEL, A. A contribuição para repensar... a educação algébrica elementar. Pró-posições, v. 4, n. 1, p. 78-91, 1993.

BRASIL. Referenciais para formação de Professores. Secretaria de Educação Fundamental. Brasília. DF, 2000.

FONSECA, Maria da Conceição Ferreira Reis. Conceito(s) de numeramento e relações com o letramento. In: LOPES, Celi Espasadin; NACARATO, Adair Mendes. (Orgs.). Educação Matemática, leitura e escrita: armadilhas, utopias e realidade. Campinas: Mercado de Letras, 2009. p. 47-60.

FONSECA, Maria da Conceição Ferreira Reis. Práticas de Numeramento na EJA. In: CATELli JR, Roberto (Org.). Formação e Práticas na Educação de Jovens e Adultos. São Paulo: Ação Educativa, 2017, v.1, p. 105-115. 
FONSECA, Maria da Conceição Ferreira Reis. Sobre a adoção do conceito de numeramento no desenvolvimento de pesquisas e práticas pedagógicas na Educação Matemática de jovens e adultos. Anais do IX ENEM, 2007. Belo Horizonte: UNI-BH, 2007. Disponível em:

http://sbem.iuri0094.hospedagemdesites.ws/anais/ix_enem/Palestra/PalestraNumeramentoTex to.doc. Acesso em: 16 de jul. de 2020.

JOSSO, Marie-Christine. Caminhar para si. Porto Alegre: EDIPUCRS, 2010.

JOSSO, Marie-Christine. Experiências de vida e formação. São Paulo: Cortez, 2004.

LORENZATO, Sérgio. Para aprender matemática. Campinas, SP: Autores associados, 2006.

MENDES, Jackeline Rodrigues. Matemática e Práticas Sociais: uma discussão na Perspectiva do Numeramento. In: MENDES, Jackeline Rodrigues; GRANDO, Regina Celia (org).

Matemática e Produção de Conhecimento: Múltiplos Olhares. São Paulo: Musa, 2007.

NACARATO, Adair Mendes; MENGALI, Brenda Leme da Silva; PASSOS, Cármen Lúcia Brancaglion. A formação matemática das professoras polivalentes: algumas perspectivas para práticas e investigações. In: NACARATO, Adair Mendes. A matemática nos anos iniciais do ensino fundamental: tecendo fios do ensinar e do aprender. Belo Horizonte: Autêntica, 2009.

NÓVOA, António. O passado e o presente dos professores. In: NÓVOA, António. Profissão Professor. 2. ed. Porto: Porto Editora, 1995. pp. 13-33.

PASSOS, Carmem Lúcia Brancaglion; NACARATO, Adair. Trajetória e perspectivas para o ensino de Matemática nos anos iniciais. Estudos Avançados, v. 32, n. 94, p. 119-135, 13 dez. 2018. Disponível em: http://www.revistas.usp.br/eav/article/view/152683. Acesso em: 25 abr. de 2020.

PEREIRA, Antonio. Currículo e formação de educadores sociais na pedagogia social: relato de uma pesquisa-formação. Revista Profissão Docente. Uberaba, MG, v. 13, n. 29, p. 9-35, jul./dez., 2013. Disponível em:

http://www.revistas.uniube.br/index.php/rpd/article/view/545/731. Acesso em: 25 de fev. 2019.

PIMENTA, Selma Garrido. O estágio na formação de professores: Unidade teoria e prática? 11. ed. São Paulo, SP: Cortez, 2012.

PONS, Juan de Pablos. Visões e conceitos sobre a tecnologia educacional. In: SANCHO, Juana María (org.). Para uma tecnologia educacional. Porto alegre: Artmed, 2001.

SANCHO, Juana María. A tecnologia: um modo de transformar o mundo carregado de ambivalência In: SANCHO, Juana María (org.). Para uma tecnologia educacional. Porto alegre: Artmed, 2001. 


\section{APÊNDICE 1}

\section{AGRADECIMENTOS}

Em todo tempo da realização da pesquisa os encontros de estudo-formação foram muito importantes para a constituição do texto apresentado, diante disso agradeço aos participantes do grupo (GELEN) e reflexões sobre a formação teórica e prática.

\section{FINANCIAMENTO}

Não se aplica.

\section{CONTRIBUIÇÕES DE AUTORIA}

Resumo/Abstract/Resumen: Rosimeire Aparecida Rodrigues

Introdução: Rosimeire Aparecida Rodrigues

Referencial teórico: Rosimeire Aparecida Rodrigues

Análise de dados: Rosimeire Aparecida Rodrigues

Discussão dos resultados: Rosimeire Aparecida Rodrigues

Conclusão e considerações finais: Rosimeire Aparecida Rodrigues

Referências: Rosimeire Aparecida Rodrigues

Revisão do manuscrito: Rosimeire Aparecida Rodrigues

Aprovação da versão final publicada: Rosimeire Aparecida Rodrigues

\section{CONFLITOS DE INTERESSE}

A autora declarara não haver nenhum conflito de interesse de ordem pessoal, comercial, acadêmico, político e financeiro referente a este manuscrito.

\section{DISPONIBILIDADE DE DADOS DE PESQUISA}

A autora declara que disponibilizara os dados referentes a esta pesquisa a quem solicitar, por meio das informações de contato supracitadas.

\section{CONSENTIMENTO DE USO DE IMAGEM}

Não se aplica.

\section{APROVAÇÃO DE COMITÊ DE ÉTICA EM PESQUISA}

$\mathrm{Eu}$, Rosimeire Aparecida Rodrigues, declaro que a pesquisa foi aprovada por Comitê de Ética em Pesquisa com seres humanos (Número do Parecer: 3.615.322), Certificado de Apresentação de Apreciação Ética (CAAE no 10530919.6.0000.5519), gerado pela CONEP, do projeto de pesquisa oriundo deste artigo.

\section{COMO CITAR - ABNT}

RODRIGUES, Rosimeire Aparecida. A formação inicial de professores para o ensino de matemática na EJA uma experiência vivenciada no GELEN. REAMEC - Rede Amazônica de Educação em Ciências e Matemática. Cuiabá, v. 9, n. 2, e21064, maio a agosto, 2021. https://doi.org/10.26571/reamec.v9i2.12857

\section{COMO CITAR - APA}

Rodrigues, R. A. (2021). A formação inicial de professores para o ensino de matemática na EJA uma experiência vivenciada no GELEN. REAMEC - Rede Amazônica de Educação em Ciências e Matemática, 9(2), e21064. https://doi.org/10.26571/reamec.v9i2.12857

\section{LICENÇA DE USO}

Licenciado sob a Licença Creative Commons Attribution-NonCommercial 4.0 International (CC BY-NC 4.0). Esta licença permite compartilhar, copiar, redistribuir o manuscrito em qualquer meio ou formato. Além disso, permite adaptar, remixar, transformar e construir sobre o material, desde que seja atribuído o devido crédito de autoria e publicação inicial neste periódico.

\section{DIREITOS AUTORAIS}

Os direitos autorais são mantidos pelos autores, os quais concedem à Revista REAMEC - Rede Amazônica de Educação em Ciências e Matemática - os direitos exclusivos de primeira publicação. Os autores não serão 
remunerados pela publicação de trabalhos neste periódico. Os autores têm autorização para assumir contratos adicionais separadamente, para distribuição não exclusiva da versão do trabalho publicada neste periódico (ex.: publicar em repositório institucional, em site pessoal, publicar uma tradução, ou como capítulo de livro), com reconhecimento de autoria e publicação inicial neste periódico. Os editores da Revista têm o direito de proceder a ajustes textuais e de adequação às normas da publicação.

\section{PUBLISHER}

Universidade Federal de Mato Grosso. Programa de Pós-graduação em Educação em Ciências e Matemática (PPGECEM) da Rede Amazônica de Educação em Ciências e Matemática (REAMEC). Publicação no Portal de Periódicos UFMT. As ideias expressadas neste artigo são de responsabilidade de seus autores, não representando, necessariamente, a opinião dos editores ou da referida universidade.

\section{EDITOR}

Dailson Evangelista Costa

\section{HISTÓRICO}

Submetido: 28 de julho de 2021.

Aprovado: 12 de agosto de 2021.

Publicado: 28 de agosto de 2021. 